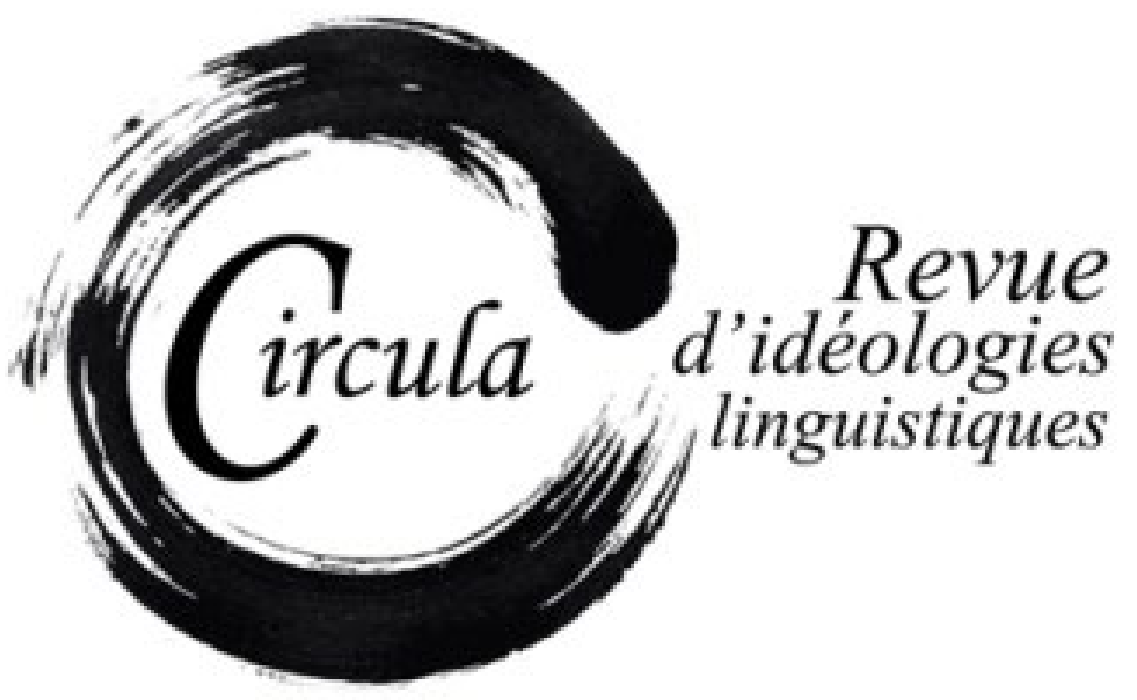

TITRE: LENGUA, POLÍTICA Y EDUCACIÓN EN EL CHILE DEL SIGLO XIX: IDEOLOGÍAS LINGÜÍSTICAS EN LAS CoRRECCIONES LEXIGRÁFICAS (1860) DE VALENTín GORMAZ

Auteur(s): Darío Rojas, Universidad DE CHILE

Revue: CirCula, NUMÉRO 4

PAgES: $63-86$

ISSN: 2369-6761

DiRecteurs: Wim Remysen et SABIne SchWARZE

URI: HTTP://HDL.HANDLE.NET/11143/10177

DOI: $10.17118 / 11143 / 10177$ 


\section{Lengua, política y educación en el Chile del siglo XIX: ideologías lingüísticas en las Correcciones lexigráficas (1860) de Valentín Gormaz}

Darío Rojas, Universidad de Chile darioroj@u.uchile.cl

Resumen: Analizamos las Correcciones lexigráficas sobre la lengua castellana en Chile (1860), de Valentín Gormaz, en términos de sus ideologías y actitudes lingüísticas hacia la variación de la lengua española. Mostramos que en la ideología lingüística de este autor hay una relación estrecha entre lengua, política y educación, pues considera que la educación idiomática (el propósito al que intenta contribuir su obra) es funcional para la formación de ciudadanos. Gormaz despliega una versión circunstanciada de la ideología de la lengua estándar, que toma como modelo la norma castellana (objeto de actitud positiva) e intenta orientar las conductas idiomáticas de los educandos chilenos hacia ella, a la vez que intenta apartarlas de las variantes dialectales chilenas, que son objeto de actitud negativa.

Palabras clave: ideologías lingüísticas; actitudes lingüísticas; historiografía lingüística; lexicografía chilena; español de Chile; Valentín Gormaz

Abstract: We study language ideologies and attitudes towards Spanish language variation in Correcciones lexigráficas sobre la lengua castellana en Chile (1860), by Valentín Gormaz. We show that Gormaz's language ideology links language, politics and education by establishing that language education (the main purpose of his work) contributes to the construction of the citizen. Gormaz exhibits a context-specific version of the standard language ideology: he chooses the Castilian norm as the standard, he shows positive attitudes towards it, and he intends to enforce this norm on Chilean students while eradicating their vernacular variety of Spanish, which in turn is subject to negative attitudes.

Keywords: language ideologies; language attitudes; linguistic historiography; Chilean lexicography; Chilean Spanish; Valentín Gormaz 


\section{Introducción ${ }^{1}$}

El siglo XIX ve surgir, en Chile y en general en Hispanoamérica, debido a los procesos de independencia y formación de nuevos Estados, una intensa reflexión metalingüística que Del Valle y Gabriel-Stheeman (2004) califican como "la batalla del idioma", siguiendo una afortunada descripción de Carlos Rama. En mayor o menor grado, la lengua española se erigió como un objeto simbólico cuya representación social legítima fue disputada y construida discursivamente a través de lo que Blommaert (1999) denomina debates lingüístico-ideológicos. De este modo, los discursos acerca de la lengua española de dicha época son observatorio privilegiado para estudiar la formación y reproducción de ideologías y actitudes lingüísticas que muchas veces continúan vigentes en la actualidad.

Durante la primera mitad del XIX, estos debates tuvieron como principales protagonistas una corriente de pensamiento racionalista, representada por Andrés Bello, y otra romántica, representada por Domingo F. Sarmiento (Torrejón, 1989). Estas dos corrientes se contraponían, por ejemplo, en su valoración de los rasgos dialectales (negativa, en el caso del racionalismo, por atentar contra una deseada unidad del idioma; positiva, en el caso del romanticismo, por considerarlos símbolos de identidad), pero coincidían en otorgar un lugar central a la educación lingüística en la formación de los ciudadanos. Esto debe entenderse en el marco más general de la centralidad que en la época independiente tuvo la educación, que "no es 'una' política, sino que 'es' política porque se le concibe desde y en función de la nueva soberanía” (Serrano, 2010: 30). En este contexto, la lengua, como destaca Arnoux, es un instrumento político de cuya relevancia está plenamente consciente la élite gobernante:

La representación de la lengua legítima que la gramática nacional formula como patrón al que deben ajustarse las prácticas debe ser reconocida por la población del territorio para asegurar su carácter de común en la extensión del Estado. Para ello es imprescindible su circulación por el sistema educativo, que a su vez debe ir ampliándose. (Arnoux, 2008: 25-26)

La necesidad de instrumentos lingüísticos (diccionarios y gramáticas) que cumplieran un rol auxiliar en este proceso de educación lingüística encontró respuesta no solo en el medio local, sino también en el extranjero. Fuera de las obras de la Academia, los libreros franceses o los españoles exiliados por razones políticas en Francia publicaron varias gramáticas y diccionarios (abiertamente basados en las obras académicas) con el fin de ser comercializados en América, comercio facilitado además por las circunstancias políticas del momento:

1. Proyecto FONDECYT 1150127, CONICYT, Gobierno de Chile. Agradezco los comentarios y sugerencias de dos evaluadores anónimos, que contribuyeron sustancialmente a mejorar la calidad de este trabajo. 
El hecho de que España dejara de proveer libros a las antiguas colonias españolas de América, supuso una gran oportunidad de mercado para los libreros y editores franceses. De este modo, se emprendió el camino de la lexicografía comercial para satisfacer las necesidades del público hispanoamericano. (Trujillo-González, 2013: 11)

Entre los españoles exiliados que destacaron en este rubro, se encuentran Manuel Núñez de Taboada (autor de un Diccionario de la lengua castellana publicado en 1825), Cristóbal Pla y Torres (Diccionario de la lengua castellana, por la Real Academia Española, de 1826) y, en lugar sobresaliente, el valenciano Vicente Salvá, autor de un diccionario "con algunas mejoras" respecto del de la Academia, publicado en 1838, y del conocido Nuevo diccionario de la lengua castellana, aparecido en París en 1846, y que tendría once ediciones hasta 1894 (Azorín Fernández, 2003).

A modo de ejemplo de la influencia de estos lexicógrafos en América, puede mencionarse que el Nuevo diccionario de Salvá llegó a competir en el mercado americano con el de la RAE (del cual, en todo caso, tomó gran parte de su caudal lexicográfico). El mismo Salvá, que vivió en París desde 1830, reconoció que su obra tenía como público principal al americano, y que esta decisión era de carácter fundamentalmente comercial. Asimismo, su Gramática de la lengua castellana según ahora se habla (1830), influenciada por los ideólogos franceses, tuvo un ascendiente importante sobre, por ejemplo, algunos de los principios aplicados por Bello en su Gramática (Roca Franquesa, 1953) o sobre las gramáticas académicas de 1854 y 1870 (Girón Alconchel, 2007).

En dicho contexto histórico, las Correcciones lexigráficas sobre la lengua castellana en Chile de Valentín Gormaz son especialmente interesantes por su carácter pionero en la reflexión metalingüística chilena de la segunda mitad del XIX. Rojas Carrasco (1940) considera que las Correcciones son la primera obra lexicológica producida en el medio chileno, a lo que cabe precisar que, además de obra lexicológica, es obra también ortográfica y gramatical, como demuestran sus extensos apéndices dedicados a la conjugación de verbos, formación de plurales, acentuación gráfica y “letras del alfabeto que pudieran causar alguna dificultad", junto con un extenso vocabulario ortográfico; en total, todos estos apéndices ocupan más de la mitad del libro. Además, Mario Ferreccio identifica en las Correcciones lexigráficas un "valor eje [...] del que se genera la más formidable máquina de consignas lingüísticas, que perduran hasta hoy" (1979: 40). Es decir, ve en esta obra un rol generador del tejido intertextual que se comienza a construir en la actividad filológica chilena durante el siglo XIX. De hecho, Zorobabel Rodríguez, en su Diccionario de chilenismos (1875), en varias ocasiones hace referencia al texto de Gormaz, normalmente para mostrar su desacuerdo con él. Incluso Andrés Bello consideró digno de comentario este opúsculo (Rojas 2015). 
Pensamos que, para comprender mejor esta obra, debe entendérsela en relación con el género de los diccionarios de provincialismos (Haensch, 2000), a pesar de no considerársela habitualmente como parte de este ${ }^{2}$. Numerosos trabajos de este tipo se propusieron coleccionar alfabéticamente comentarios de tipo normativo-didáctico respecto de rasgos lingüísticos considerados por los autores como provincialismos particulares de cada país o de regiones geopolíticas mayores. Por su carácter de provincialismos, el estatus normativo de estos usos (es decir, su carácter "correcto/ aceptable" o "incorrecto/inaceptable") se encontraba sujeto a discusión. Los autores de estos textos entregan argumentos para justificar su evaluación de los fenómenos idiomáticos cuestionables o cuestionados ya por otros autores ${ }^{3}$.

Según nuestro parecer, estos diccionarios pueden considerarse parte de una familia mayor de textos, con los que comparten el propósito normativo-didáctico, pero de los que se diferencian por el carácter no estrictamente lexicográfico que poseen estos últimos, es decir, por poseer una macroestructura y una microestructura distintas a la habitual en los diccionarios. Ejemplos de estos "parientes" de los diccionarios de provincialismos en el contexto chileno son el Catálogo anónimo de 1843, una especie de Appendix Probi local ${ }^{4}$ (Ferreccio, 1979), y las Correcciones lexigráficas sobre la lengua castellana en Chile de Valentín Gormaz, que estudiaremos en el presente trabajo.

Las diferencias macro y microestructurales pueden apreciarse claramente si se comparan las Correcciones de Gormaz con el primer diccionario de provincialismos hecho en América, el Diccionario provincial de voces cubanas de Esteban Pichardo, de 1836 (véase Camacho, 2003-2004 y Chuchuy, 1994: 84-86). El de Pichardo es el diccionario de provincialismos prototípico: además de un prólogo, el núcleo de la obra corresponde a una lista de lemas ordenada alfabéticamente. Cada uno de estos lemas es acompañado de marcas (de categoría gramatical o de otro tipo) y, la mayoría de las veces, de una definición lexicográfica a la usanza de las que se pueden encontrar en los diccionarios académicos de la época (a veces cargadas al enciclopedismo, lo que aumenta su extensión); otras veces ocupa el lugar de la definición algún comentario normativo. En cambio, en Gormaz, como veremos más adelante, nos encontramos con una macroestructura muy distinta y con una microestructura que no tiene a la definición como elemento central; de hecho, es raro encontrar definiciones. Pero, a pesar de estas diferencias, las obras de Pichardo y de Gormaz comparten una finalidad normativa básica, que al parecer satisfacía de mejor manera el propósito didáctico mediante el ordenamiento alfabético de los lemas que servían de vía de acceso para los fenómenos idiomáticos comentados. Las diferencias, según nuestra opinión, son más de forma que de fondo.

2. Véase, por ejemplo, el catálogo que Matus (1994) hace sobre las obras chilenas, según el cual el diccionario de Rodríguez, de 1875, sería el primer diccionario de provincialismos chilenos.

3. Véase Rojas (2010) para un desarrollo inicial de esta idea.

4. El Catálogo anónimo, a pesar de hallarse referencias a él en algunos catálogos bibliográficos, no fue conocido ampliamente sino hasta que Mario Ferreccio encontró el impreso en la Biblioteca Nacional de Santiago de Chile, hacia 1970 y lo publicó en una revista científica chilena. El Catálogo, fechado en 1843, "está en el espíritu de las preocupaciones y querellas idiomáticas que se encienden entre nosotros [los chilenos] por el año 40 del siglo pasado" (Ferreccio, 1979: 43). 


\section{El autor}

No disponemos de mucha información biográfica ${ }^{5}$ acerca de Valentín Gormaz Gutiérrez de Espejo, lo cual probablemente se pueda atribuir al bajo perfil público que tuvo en comparación con personajes como Andrés Bello, los Amunátegui o Zorobabel Rodríguez.

Nacido en Santiago en 1820 y muerto en 1884, Gormaz se tituló de abogado en 1841 y al parecer se dedicó mayormente al ámbito judicial, tanto en cuanto oficio (ocupó el cargo de Defensor de Menores) como en cuanto interés erudito (publicó varios trabajos sobre materias jurídicas). También fue diputado suplente por Linares entre 1867 y 1870. Sus trabajos sobre asuntos jurídicos, como decíamos, son varios: un Índice alfabético de las materias contenidas en el Código Civil chileno (1857), un Índice alfabético del Código de Comercio chileno (1869) y un Repertorio de jurisprudencia teórica y práctica chilena durante los últimos 30 años (1873).

Puede concluirse, por tanto, que su obra lingüística, manifestada únicamente en las Correcciones lexigráficas sobre la lengua castellana en Chile, seguidas de varios apéndices importantes; dispuestas por órden alfabético y dedicadas a la instrucción primaria, publicadas en Valparaíso en 1860, ocuparon un lugar marginal en el contexto de sus actividades intelectuales.

\section{Ideologías y actitudes en las Correcciones lexigráficas}

\subsection{La "Advertencia" preliminar}

Las Correcciones de Gormaz principian con una breve "Advertencia" preliminar. La finalidad didáctica escolar del libro de Gormaz es evidente ya desde su título, que indica que están "dedicadas a la instrucción primaria". En la "Advertencia", el autor se encarga de reforzar esta idea:

[E]s innegable, que a pesar de la atencion que se ha prestado a estudios superiores; del fortísimo impulso dado a la instruccion primaria; y del jeneral desarrollo operado en todo jénero de adelantos, se ha avanzado bien poco en materia de lexigrafía; y bajo este respecto podemos reclamar un título de oportunidad. No acusa esto una indiferencia apática y censurable, ni el desconocimiento de la importancia de un estudio que, segun el sentir de un sabio escritor americano, "es indispensable a aquellas personas que por el lugar que ocupan en la sociedad, no podrian sin degradarse descubrir en su lenguaje resabios de vulgaridad o ignorancia, y cuya omision desluce al orador, y puede hasta hacerle ridículo y concitarle el desprecio de sus

5. La escasa información que hemos podido recolectar proviene de, en cuanto a su biografía, del sitio http://historiapolitica.bcn.cl/resenas_parlamentarias/wiki/Valent\%C3\%ADn_Gormaz_Espejo; y en cuanto a sus obras, de los catálogos de la Biblioteca Nacional de Chile y de la Biblioteca del Congreso Nacional chileno. 
oyentes." Se esplica su vacio con la preferente atencion que naturalmente se otorga a cosas de mas bulto, y la facilidad con que pasan entre ellas las de pequeña nota. (Gormaz, 1860: v)

Es decir, Gormaz, con optimismo, piensa que el descuido de los estudios lingüísticos en Chile no se debe a que se los haya considerado irrelevantes, sino a que, durante la primera mitad del XIX, momento en que se desplegaban múltiples esfuerzos, en diversos ámbitos, para la conformación del nuevo Estado chileno, la atención dedicada al tema del lenguaje pudo verse sobrepasada por la urgencia con que era necesario atender, por ejemplo, a la estabilización del Gobierno o a asuntos militares, por mencionar algunos de los más relevantes para el periodo. En el fondo, Gormaz quiere reposicionar a los estudios lingüísticos (entendidos como actividad normativa) en su debido lugar entre las preocupaciones políticas nacionales.

Más adelante, el autor agradece al Estado chileno por el apoyo económico prestado a la publicación, resaltando precisamente lo que él considera la razón de dicho apoyo, a saber, la urgencia de la educación: "El Supremo gobierno, solícito siempre por cuanto puede mejorar o contribuir al adelanto de la instrucción pública, ha dado prestijio a esta obra con una jenerosa suscricion" (Gormaz, 1860: vii).

Quizá dentro de un movimiento retórico de captatio benevolentiae, Gormaz destaca que, sin embargo, su obra solo puede cumplir una función auxiliar en la educación lingüística, es decir, no pretende convertirse en un manual escolar de referencia obligada:

En cuanto al objeto de esta obra, nuestro propósito ha sido el procurar un aprendizaje práctico sin el engorro de estudios dilatados, que muchos no pueden o no quieren sobrellevar; indicar solo lo malo que se habla o se escribe; y sin agobiar con preceptos y reglas, presentar las correcciones como en un cuadro que sea facilísimo consultar. Por aquí se verá, pues, que nuestro plan no ha sido hacer gramáticas ni tratados completos de cosa alguna, sino solo suplir vacios y enseñar sin trabajo a los que necesiten aprovecharlo; dejando a otros mas competentes el llenar la tarea. (Gormaz, 1860:v)

La educación, en el pensamiento de Gormaz, como en el de muchos otros intelectuales chilenos de la época (Serrano, 2010), está vinculada con la noción de progreso, y es precisamente en este concepto donde el autor ubica la motivación última de su obra, que aparece presentada entonces como una verdadera tarea patriótica:

La marcha de progreso que trae el país desde diez años ha, es una llamada de forzosa contribucion a que todos debemos responder con el continjente que esté a nuestros alcances. Esta consideracion nos ha movido, en despecho de nuestro amor propio, a sacar a luz los apuntes que damos al público, destinados esclusivamente a un uso privado. (Gormaz, 1860: v) 
También en la "Advertencia", Gormaz abunda en los efectos indeseables que conllevaría el descuido de la labor lingüístico-educativa materializada en obras como la suya. Entre ellas, Gormaz destaca las consecuencias comunicativas (y, en última instancia, cívicas) de la falta de educación lingüística entre los ciudadanos (carencia que con su obra pretende ayudar a remediar). En una nota a pie de página, Gormaz se detiene en ilustrar un ejemplo de los "conflictos y compromisos" que podría acarrear dicho tipo de desconocimiento:

En efecto, supóngase la existencia de un precepto legal que prohibiera cargar armas. Supóngase tambien que se esceptuara en él a los carniceros, pescadores y demas que las necesitan para su mercado, y que por efecto de propiedad, se empleara la voz pescador en lugar de pescadero como es tan jeneral entre nosotros. ¿Qué haria el juez con un vendedor de pescado, a quien se acusara del delito de cargar armas prohibidas, y a quien se negara su profesion de pescador? Y viceversa; si el acusado es uno de esos cuyo oficio es pescar ¿cómo se acomodaria con él? Al tenor de esto, hai muchas otras voces de uso vulgar anfibolójico que pueden hacer zozobrar; y para evitar esto, no se conoce mas remedio que la propiedad, la exactitud, y un poco de estudio sobre lo que llevamos diariamente entre manos, y hemos menester en los mas importantes actos de la vida. (Gormaz, 1860: v)

Nótese bien que, en el ejemplo de Gormaz, el problema se origina en el hecho de que en Chile, a diferencia de lo que sucedía en la lengua estándar codificada por la RAE, pescador era una palabra polisémica: podía significar tanto 'el que vende pescado' como 'el que pesca'. La lengua estándar, en cambio, distinguía entre pescador 'el que pesca' y pescadero 'el que vende pescado'. En este caso, la lengua estándar presenta para Gormaz la ventaja de ser más "exacta", de tener un par de palabras con significados "propios", es decir, unívocos, en lugar de una sola palabra con más de un significado.

En este punto en particular, Gormaz muestra una actitud negativa hacia la polisemia, fenómeno sobre el que ya había llamado la atención, en el contexto chileno, Andrés Bello ${ }^{6}$. La actitud de rechazo hacia la polisemia (junto con otras ideas de Gormaz) puede interpretarse, según nuestro parecer, como una manifestación de la ideología de la lengua estándar (Milroy, 2001). La polisemia es un rasgo inherente al lenguaje humano, a pesar de lo cual, en diversas épocas y lugares, ha sido objeto de actitudes negativas (Trudgill, 1998). La estandarización se focaliza, según Milroy y Milroy (1999), en la reducción de la variación. Puede pensarse, en consecuencia, que quienes se adhieran a la ideología del estándar y sientan necesario el proceso de estandarización verán con malos ojos la polisemia porque esta implica la existencia de más de un significado para una única forma léxica, esto es, la existencia de variación semasiológica.

6. "Hay otro vicio peor, que es el prestar acepciones nuevas a las palabras y frases conocidas, multiplicando las anfibologías de que por la variedad de significados de cada palabra adolecen más o menos las lenguas todas, y acaso en mayor proporción las que más se cultivan, por el casi infinito número de ideas a que es preciso acomodar un número necesariamente limitado de signos" (Bello, 1847: xi). 
Nótese, además, el énfasis que pone Gormaz, al comentar su ejemplo, en los efectos extralingüísticos, políticos y cívicos, que resultan del equívoco. No parece casual que el ejemplo aluda al porte de armas y al ejercicio de las profesiones, y que tenga por contexto el ámbito judicial, asuntos cívicos que con seguridad tuvieron prominencia en la vida social del Chile del siglo XIX, y que constituyen solo una muestra de "los mas importantes actos de la vida" en los que, según Gormaz, es de la mayor necesidad el conocimiento profundo del lenguaje.

Otro asunto que merece comentario, en cuanto a la "Advertencia", es el de las fuentes que el propio autor declara haber usado como referencia idiomática. Gormaz, claramente, se basa en un corpus que delimita una forma bien específica, de impronta peninsular, para el modelo ideal de lengua que se debe enseñar en la educación chilena:

He tenido a la mano para la confeccion de este trabajo el diccionario de Arnao, el de la Academia, el de D. Vicente Salvá, los de sinónimos de Jonama, Huerta y Olive, las gramáticas de los Sres. Bello, Salvá y Matinez Lopez; y la Ortolojía de los Sres. Sicilia, Bello y Salvá. En la doctrina de los nombres y ortografia, he seguido a la Academia, cuidando, empero, de advertir lo que agrega o en lo que difiere el Sr. Salvá. En las conjugaciones he tomado por punto de partida la doctrina de este último; aunque mi opinion, de distinta escuela, no marchaba conforme en muchos casos que he cuidado igualmente de anotar. Como los verbos en iar y uar presentan sus dificultades especiales, he creido conveniente agregar las reglas que les son respectivas, copiándolas casi textualmente de Salvá, pero agregando las discordancias de Bello y Sicilia. De estos tres últimos he tomado lo mas, respecto a acentuacion; y de los dos primeros y de Martinez Lopez, he acopiado lo relativo a formacion de plurales. El estracto sobre las letras, es doctrina de Salvá, y la nomenclatura final de voces, del Sr. Martinez Lopez, como ya lo indicamos en la nota del caso. (Gormaz, 1860: vi-vii)

Todas estas fuentes tienen índole normativa. Como es de esperar, las obras de la Academia española se encuentran entre los principales textos que encarnan el modelo lingüístico seguido por Gormaz. Pero nótese que también otorga mucha importancia a la obra de individuos, especialmente a Andrés Bello y Vicente Salvá.

En cuanto a Bello, las razones de su influencia en Gormaz son obvias. La presencia del lexicógrafo y gramático valenciano Vicente Salvá puede entenderse en función de la influencia que sus obras normativas, especialmente su Nuevo diccionario de la lengua castellana, tuvieron en América.

Finalmente, Gormaz ofrece una clasificación de los tipos de "correcciones" que incluye en su obra: 
1. nombres que poco se conocen o no se usan; empobreciendo asi el idioma: $2 .{ }^{\circ}$ nombres anticuados que deben reemplazarse por los que espresamos: $3 .^{\circ}$ nombres que se toman en distinta significacion; y en ellos apuntamos aquel por que deben sustituirse, y damos por medio de una nota el significado del que se suplanta; para que se adquiera su conocimiento: lo cual dá a entender el agregado -en sentido de; es decir, que se dice mal, en el sentido del nombre que nosotros damos a luz y que es el que debe emplearse; siendo tambien propio el otro, pero en la diferente acepcion esplicada en la nota. Por ejemplo, la palabra abalear que suponemos mal usada en sentido de fusilar; no lo es absolutamente; porque en sentido de limpiar el trigo, es mui castiza: 4., por último, nombres a que se dá una denominacion arbitraria, y entonces decimos -no existe; dando nosotros el respectivo equivalente. (Gormaz, 1860: vii)

Estos tipos de correcciones pueden ser relacionados con distintas suposiciones del autor, reveladoras de su ideología lingüística, acerca de cómo hablaban los chilenos de esa época la lengua castellana. En el tipo 1, Gormaz ofrece una ayuda supletoria, es decir, contribuye a paliar una supuesta falta de repertorio léxico de los hablantes chilenos. Para el autor, entonces, el habla de los chilenos adolece de pobreza de vocabulario. En el tipo 2, queda claro que Gormaz considera que los arcaísmos léxicos no son propios del buen hablar, por lo cual informa a los lectores acerca de cuáles son las formas apropiadas en el estándar moderno. Otro problema del que adolece el habla chilena, entonces, es la presencia de arcaísmos. En el tipo 3, Gormaz vuelve a ofrecer una ayuda supletoria, pero esta vez no se trata del desconocimiento de vocablos, sino del desconocimiento de cuál es el significado "correcto" de estos vocablos: casos en que una palabra se usa en el sentido de otra. Al enunciar Gormaz que en estos casos "se dice mal", queda muy clara su actitud hacia dicha conducta lingüística. El tercer defecto del castellano de Chile, entonces, sería la equivocación en cuanto al uso semánticamente preciso del vocabulario. Por último, en el tipo 4, Gormaz denuncia usos "inexistentes", con lo cual quiere decir que dichas palabras no se encuentran en los códigos del estándar. La cuarta característica indeseable del habla chilena, por tanto, sería el inventar vocablos, ignorando los límites impuestos por el estándar.

En síntesis: los chilenos, en su uso de la lengua castellana, desconocen vocablos, no saben usarlos bien, inventan otros y adolecen de arcaísmo. Estas serían las razones que motivan el acto de higiene verbal (Cameron, 1995) realizado por Gormaz y materializado en sus Correcciones lexigráficas. 


\subsection{Las "Correcciones lexigráficas"}

A continuación del texto preliminar, las "Correcciones" mismas se disponen en una lista alfabética, a la manera de un Appendix Probi, que ocupa 9 páginas. La lista se dispone en dos columnas, encabezadas con las fórmulas Se dice mal y Debe decirse, y además incluye aseveraciones del tipo no existe, todas en cursivas, y una serie de notas, añadidas tras los apéndices, y a las que se hace referencia con números entre paréntesis, en las que Gormaz explica con mayor detalle las razones de sus juicios. Copiamos a continuación el comienzo de la lista, para que el lector pueda hacerse una idea de su disposición discursiva:

\begin{tabular}{|c|c|}
\hline Se dice mal. & debe decirse. \\
\hline Abajada; abajar, anticuado & Bajada; bajar. \\
\hline Abalear (1), en sent. de & Fusilar. \\
\hline Abanderarse, no existe & Abanderizarse. \\
\hline Abarrotar (2), en sentido de & Amollar. \\
\hline Abastero, no existe & Abastecedor. \\
\hline Ablandadura, ant & Ablandamiento. \\
\hline Abotonadura, ant & Botonadura. \\
\hline Abricias, no existe & Albricias. \\
\hline Abrochadura, ant & Abrochamiento. \\
\hline Abullar, no existe & Ahullar. \\
\hline Abundamiento & Abundancia. \\
\hline Abur, no existe & Agur. \\
\hline Abusionero, anticuado & Agorero. \\
\hline Abutagarse, no existe & Abotagarse. \\
\hline Acangrenarse, no ex & Agangrenarse. \\
\hline Acarreadura, anticuado & Acarreo. \\
\hline \multicolumn{2}{|l|}{ Acerico (3) } \\
\hline Acesar, no existe & Jadear. \\
\hline \multicolumn{2}{|l|}{ Acetre (4) } \\
\hline Accido, no existe & Ácido. \\
\hline Aconchado (5), en sentido de & Borroso; brozoso. \\
\hline Achucharrar (6), en sentido de abrasarse, no existe & Achicharrar. \\
\hline Achicharrar (7), en sentido de aplastar, no existe & Achuchar. \\
\hline
\end{tabular}


Las fórmulas que encabezan las columnas establecen, desde un principio, valoraciones muy explícitas de los usos lingüísticos consignados, es decir, muestran actitudes lingüísticas. Lo que está en la columna izquierda cae bajo la categoría de lo que "se dice mal". Esto es expresado por Gormaz con un adverbio axiológico que evalúa la conducta lingüística, de polaridad negativa ( $m a$ l). Lo de la columna derecha, por otro lado, es lo que según Gormaz "se debe decir": acá usa el verbo modal de obligación deber, referido al hablar. De acuerdo con Bartsch (1982), el verbo deber especifica que el carácter de una norma es obligatorio y no optativo. En otras palabras, la norma no es permisiva. El normativismo de la obra de Gormaz, en este caso, se construye con una fuerza coercitiva mayúscula.

Como aclaraba el autor en la "Advertencia" preliminar, las expresiones de la columna izquierda se dicen "mal", en primer lugar, porque se trata de palabras que "no existen", tales como abastero, cuyo significado en realidad se expresaría mediante la palabra abastecedor. La mayoría de estos casos corresponden a variantes morfológicas (abanderarse por abanderizarse, alertear por alertar, arremilgarse por remilgarse, atornillador por destornillador) o de pronunciación (abutagarse por abotagarse, acangrenarse por agangrenarse, brigadiel por brigadier). Cabe destacar que muchas de las variantes de pronunciación consideradas por Gormaz como "inexistentes" se explican por tendencias de pronunciación características del dialecto chileno en cuanto variedad del español atlántico (Moreno Fernández, 2009): debilitamiento de /s/implosiva (arriejar por arriesgar, chijete por chisguete, hallajo por hallazgo o refalar por resbalar, todas con ensordecimiento de la consonante por influencia de la aspiración precedente), debilitamiento y neutralización de líquidas implosivas (arcancía por alcancía, balquinazo por barquinazo, palchi por parche), seseo (fresada por frazada), yeísmo (rayo por rallo) o debilitamiento de /d/ (grea por greda, obleda por oblea, con ultracorrección).

Otros ítems léxicos son objeto de actitud lingüística negativa y de censura por el hecho de ser anticuados. Es el caso de abotonadura, cuyo equivalente moderno (en tiempos de Gormaz), propio del estándar, sería botonadura, o de aguaitar, un antiguo germanismo léxico, ingresado al español a través del catalán, hasta hoy sobreviviente en el español rural y popular de Chile (DUECh, s. v. aguaitar), cuyos correspondientes castizos serían acechar y atisbar. Otros vocablos caen bajo la categoría de lo que "se dice mal" porque se usan en un sentido distinto del que les sería "propio": tal es el caso de aconchado, que en Chile se usa en el sentido de 'borroso, brozoso', para cuya expresión el estándar cuenta con estos últimos lexemas. 
Resulta interesante constatar la proporción numérica de los tipos de correcciones que consigna Gormaz: 428 veces indica que una palabra "no existe", 110 veces que la palabra se usa en un sentido impropio, y 39 veces consigna usos anticuados. En consecuencia, para Gormaz el defecto más recurrente del uso de la lengua castellana en Chile, por mucho, es el inventar palabras que "no existen" para expresar ideas que pueden referirse mediante vocablos existentes en la lengua estándar. La proporción señalada queda reflejada en el Gráfico 1:

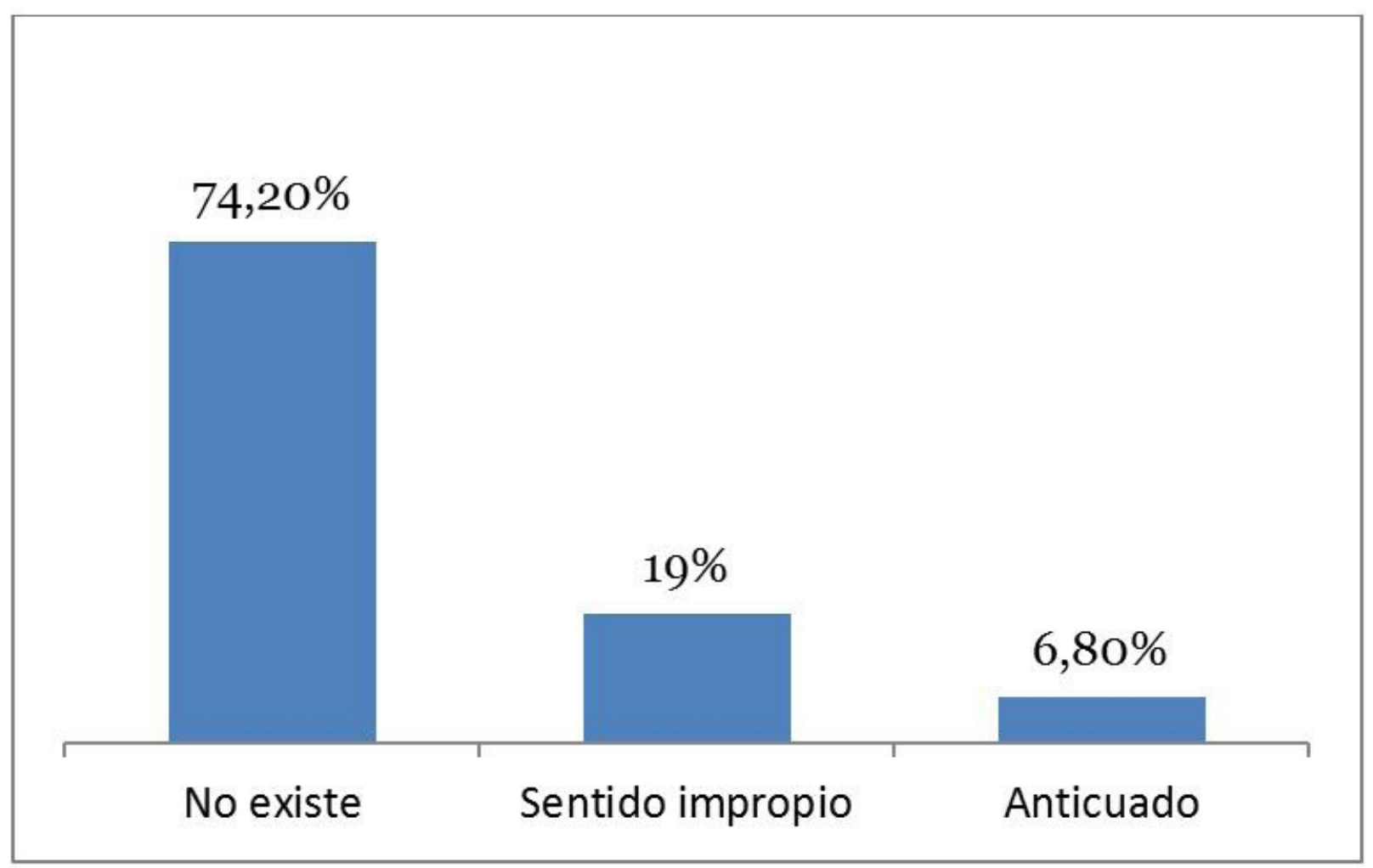

Gráfico 1. Proporción de tipos de defectos en el uso chileno de la lengua castellana, según Gormaz (porcentajes)

La declaración de "no existencia" puede entenderse mejor sobre el trasfondo del modelo cultural de la lengua descrito por Niedzielski y Preston (2003). Recuérdese que, según este modelo popular (en nuestro caso, todavía en un momento en que se encontraba vigente entre los especialistas o cuasiespecialistas), la actuación lingüística apropiada se reduce al ideal de lengua, y todo lo que se aparta del ideal (variedades regionales o sociales, por ejemplo) es catalogado como errory producto de una mera falta de competencia idiomática: es decir, al "no saber hablar". Coseriu (1990) explica este tipo de valoraciones como producto de la reducción de lo "correcto" (la conformidad de un hecho de habla con el sistema al que realiza, según la concepción estructuralista) a lo "ejemplar" (el pertenecer a una variedad de lengua particular erigida como modelo por razones determinadas)?

7. "Los 'conservadores', los puristas y, en general, quienes optan por una unidad idiomática estricta tienden a reducir lo correcto a lo ejemplar y, por consiguiente, a censurar y a pedir la eliminación de todo uso que no corresponda al tipo de ejemplaridad que preconizan y al que presentan como única 'lengua correcta’” (Coseriu, 1990: 46). 
En consecuencia, cuando Gormaz dice que un uso "no existe" quiere decir que no pertenece al estándar modélico, que queda fuera de los márgenes impuestos por este. Al habla dialectal se le niega la existencia y con ello se impone una valoración fuertemente negativa de ella: el que usa rasgos propios del dialecto vernáculo chileno simplemente no sabe hablar, tiene conductas idiomáticas inválidas, en opinión de Gormaz.

Este modelo cultural, en el fondo, remite igualmente a la ideología de la lengua estándar, según la ha descrito Milroy (2001). Esta se caracteriza por la aspiración a imponer uniformidad sobre un objeto inherentemente variable, como es el lenguaje. Como consecuencia del deseo de supresión de la variedad, se llega a considerar que solo una de las variantes o variedades coexistentes es legítima o correcta. Esta es la variante o variedad estándar, que es considerada como parámetro de calidad de todas las conductas idiomáticas, que serán, así, mejores/peores, correctas/incorrectas, bonitas/feas, etc., en la medida en que se acerquen o se alejen, respectivamente, del estándar. En el caso específico del mundo hispanohablante chileno, esta ideología motivó una actitud muy negativa hacia el habla local ("En Chile se habla muy mal”) y una actitud positiva hacia un modelo exógeno, específicamente de impronta peninsular castellana, que fue el que se adoptó como modelo normativo.

El primer apéndice de las Correcciones corresponde a "Verbos regulares". Se trata de un conjunto de listas alfabéticas de formas verbales, cada una correspondiente a formas de indicativo, de pretérito, de imperativo y de subjuntivo, respectivamente. La disposición es similar a la de las "Correcciones lexigráficas" mismas:

\begin{tabular}{|c|c|}
\hline Se dice mal. & debe decirse. \\
\hline Absuerbo & Absorbo. \\
\hline Acogotéo & Acogoto. \\
\hline Acopéo & Acópio. \\
\hline
\end{tabular}

Cabe señalar, respecto de este apéndice, que numerosas veces se corrigen formas terminadas en -ear, señalando como apropiadas las terminadas en -ar: acogoteo por acogoto, acuchilleo por acuchillo, aligereo por aligero, cateo por cato, engalaneo por engalano, pechear por pechar, etc. Es sabido que en el habla castellana de América es más común que en España el formar estos verbos denominales con el morfema -ear (NGLE-Manual, 5.2.5.d; Morales Pettorino, Quiroz y Mayorga, 1969), de modo que esto puede interpretarse como manifestación de una actitud negativa hacia un aspecto lexicogenésico específico del habla local (quizá una vertiente más de ese afán por "inventar" palabras inexistentes que Gormaz critica a los chilenos) en contraste con una consideración positiva de la forma estándar de raigambre peninsular que se encuentra objetivada en las obras normativas que Gormaz cita (RAE, Salvá, Bello, etc.). 


\subsection{Las notas a las "Correcciones"}

Tras otros apéndices", el libro concluye con 256 notas, la mayoría (148) correspondientes a las "Correcciones lexigráficas". Es en estas notas donde se puede encontrar desplegado con mayor nitidez el discurso valorativo de Gormaz respecto de los usos lingüísticos comentados.

Este discurso valorativo revela una serie de creencias y vehicula un conjunto de actitudes en relación con el uso chileno de la lengua española, las cuales resultan ser congruentes con lo que hemos venido observando en las secciones anteriores del texto de Gormaz. Algunas veces estas valoraciones reiteran las que se han manifestado anteriormente (tales como el uso del adverbio mal referido al hablar, la declaración de que un uso "no existe" y el abundante uso del verbo modal deber para expresar la obligatoriedad de usar la variante estándar), pero en muchas otras revelan nuevas aristas de la ideología y actitudes lingüísticas del autor, por lo cual las ejemplificaremos y comentaremos en lo que sigue.

Uno de los argumentos con que Gormaz justifica sus censuras es que el uso chileno es más confuso o vago que el uso estándar, que por su parte sería más claro o preciso (resaltamos los lexemas en que se expresan estas ideas):

[Se dice mal: --- / Debe decirse: anaquel] Significa la division que tienen los armarios o vasares, para poner platos, cristales etc.; y que de contínuo espresamos de un modo vago, confuso y lleno de rodeos. (Nota 20)

[Se dice mal: --- / Debe decirse: antepuertas] La palabra cortinas es mui vaga y jeneral, y nunca espresa la idea tan precisamente como antepuertas. (Nota 23)

[Se dice mal: arnés, en el sentido de / Debe decirse: jaez] Arnes, es el conjunto de armas de acero defensivas que se vestian y acomodaban al cuerpo, asegurándolas con correas y hebillas. Significa tambien, las cosas necesarias a algun objeto; y solo en este sentido tan jeneral y vago pudiera disculparse su empleo por el de jaez; pero inaceptable en nuestro concepto, clásicamente hablando. (Nota 27)

En relación con lo anterior, Gormaz también destaca la "propiedad" del uso como un factor relevante para considerarlo positivamente:

\footnotetext{
8. Al final del primer apéndice se incluye una breve sección dedicada a los "Verbos terminados en iar y uar". Luego, se incluye otra lista, esta vez dedicada a los "Verbos irregulares". Los siguientes apéndices, muy breves, explican "Reglas para saber pintar los acentos" y "Reglas para la formación de plurales". Luego sigue otro dedicado a las "Letras del alfabeto que pueden ofrecer alguna dificultad": b-v, c-z, g-j, hy m-n. Después se incluye un "Vocabulario ortográfico" bastante extenso (para ser un apéndice).
} 
[Se dice mal: aguada, en sentido de / Debe decirse: abrevadero] Aguada, es la porcion de agua que se lleva en una embarcacion; o el lugar donde hacen aguada las embarcaciones. Pero el paraje donde se dá de beber al ganado, que es lo que vulgarmente quiere espresarse con la voz aguada, debe hacerse con la de abrevadero, que es la que corresponde en propiedad, como lo indicamos. (Nota 9)

[Se dice mal: aleta, en sentido de / Debe decirse: alero] Aleta, es el conjunto de espinas unidas con una membrana que tienen los peces en el lomo, vientre, costado y cola, y con que se ayudan para nadar. En suma, lo que impropiamente se denomina gualeta entre nosotros; y cuya voz no existe, como lo advertimos en su lugar respectivo. (Nota 12)

La "promiscuidad" en el uso chileno se opone a la "distinción clara" del estándar, para nuestro autor, en lo que subyace la idea de que las palabras deben tener un significado único e inequívoco:

[Se dice mal: remonte, en sentido de / Debe decirse: remonta]. Es mui jeneral emplear promiscuamente la voz remonte, que significa solo, el acto de encumbrarse o elevarse, con la palabra remonta, que significa entre otras cosas, la compostura de las botas cuando se les pone de nuevo el zapato. (Nota 125)

[Se dice mal: bicoca, en sentido de / Debe decirse: bicoquín]. Bicoca, significa una fortificacion pequeña; una garita; una cosa de poca estimacion; mui distinto por cierto del birrete o solideo, que es lo que significa bicoquin. (Nota 33)

Gormaz refuerza esta idea cuando declara explícitamente, mediante el adverbio solo o mediante otros recursos discursivos, la univocidad semántica de varias palabras:

[Se dice mal: grosella, en sentido de / Debe decirse: grosellero]. Grosella es solo la fruta. El arbusto que dá dicha fruta, es Grosellero. (Nota 77)

[Se dice mal: taquear, no existe / Debe decirse: taconear]. Taquear, entre nosotros, se emplea en el sentido de dar tacadas con el taco, y en el de pisar con fuerza con los tacones. En ambos es mal usado; y debe sustituirse en el segundo, por el verbo dicho taconear, el cual no significa otra cosa tampoco. (Nota 135)

Otro argumento al que recurre Gormaz es el de la economía de medios de expresión, según el cual el estándar sería mejor que el uso dialectal chileno por usar menos formas lingüísticas para expresar la misma idea:

[Se dice mal: --- / Debe decirse: acetre] Significa, el caldero en que se lleva el agua bendita para las aspersiones; y que a menudo espresamos por medio de rodeos. (Nota 4)

[Se dice mal: --- / Debe decirse: alcoba] En Chile, es casi desconocida esta palabra. Siempre nos valemos de cuarto de dormir; que a la par de larga y de mal gusto, puede reemplazarse tan castiza y económicamente. (Nota 11) 
[Se dice mal: --- / Debe decirse: amamantar] Es casi jeneral decir; está dando de mamar; le dió de mamar; dále de mamar, etc. cuando empleando este verbo, nos espresamos con tanta facilidad y economía de palabras -Está amamantándolo; lo amamantó; amamántalo, etc. (Nota 17)

[Se dice mal:--- / Debe decirse: bañero] El dueño de los baños, es como decimos jeneralmente; empleando cinco palabras por una, y empobreciendo el idioma. (Nota 31)

[Se dice mal: --- / Debe decirse: triguero] Triguero, dice el diccionario, es el que comercia y trafica en trigos. Negociante en trigo; vendedor de trigos, es como se dice entre nosotros; por desconocerse casi, aquella palabra simple. (Nota 142)

En la misma dirección apunta cuando señala que el uso estándar conlleva "facilidad" de expresión:

[Se dice mal: --- / Debe decirse: amamantar] Es casi jeneral decir; está dando de mamar; le dió de mamar; dále de mamar, etc. cuando empleando este verbo, nos espresamos con tanta facilidad y economía de palabras -Está amamantándolo; lo amamantó; amamántalo, etc. (Nota 17)

[Se dice mal: --- / Debe decirse: niñero]. Lo mismo sucede con esta voz, absolutamente ignota entre nosotros. Siempre echamos mano de rodeos, para significar una idea, que puede espresarse tan sencilla como simplemente. (Nota 93)

Gormaz también considera el desconocimiento como otro factor que condiciona la incorrección con que hablan los chilenos:

[Se dice mal: --- / Debe decirse: almuerza]. No conocemos casi en Chile, cómo significar, la porcion de cosa suelta y no liquida, como granos y otras semillas, que cabe en ambas manos juntas y puestas en forma cóncava, que denota esta voz almuerza. (Nota 16)

[Se dice mal: --- / Debe decirse: peraleda]. Significa esta voz, el sitio o terreno poblado de perales; y que es casi enteramente desconocida entre nosotros. (Nota 106)

[Se dice mal: --- / Debe decirse: terregoso]. Casi es desconocido entre nosotros, el vocablo propio para significar un terreno lleno de terrones, y que denota esta voz terregoso. (Nota 137)

Al desconocimiento, por supuesto, puede confrontarse explícitamente el conocimiento idiomático:

[Se dice mal: angurria, en sentido de / Debe decirse: estangurria]. Todo el que sepa que angurria es lo mismo que sandía, verá si es exacto del sentido en que se toma aquella palabra entre nosotros. (Nota 21)

La confusión, la equivocación, el desvío de una conducta esperada, normalmente a causa de incompetencia, sea en el nivel léxico, sea en el nivel fónico, es otra de las imágenes que con frecuencia se deja ver en las justificaciones de Gormaz para censurar los usos chilenos: 
[Se dice mal: achicharrar, en sentido de aplastar, no existe / Debe decirse: achuchar]. Del mismo modo se confunde este verbo, empleándolo o tomándolo en el sentido de aplastar; cuando para tal significacion, debe adoptarse el anterior de achucharrar o achuchar, que son los que dan a entender el acto de aplastar. (Nota 7)

[Se dice mal: quínua, en sentido de / Debe decirse: quina]. Quinua, es una semilla blanca, semejante a la lenteja, que se come cocida con arroz; a diferencia de la sustancia antifebril de que se estrae la cascarilla, con que se la confunde, y que debe denominarse quina, como lo indicamos. (Nota 117)

[Se dice mal: rayo, en sentido de / Debe decirse: rallo]. Rallo, es la plancha cóncava de metal con agujeritos ásperos, con los cuales se desmenuza el pan, queso, y otras cosas, estregándolas contra él; y lo confundimos en la pronunciacion, con la voz rayo que significa el fuego eléctrico desprendido con violencia de las nubes, etc., etc. (Nota 121)

En otras ocasiones, el autor estima que el uso dialectal chileno conllevaría "mengua" o "empobrecimiento" del idioma, usando una metáfora que acude a la economía como dominio fuente:

[Se dice mal: --- / Debe decirse: niñera]. Es casi totalmente desconocida entre nosotros esta voz. La sustituimos por ama seca, con mengua del idioma y sacrificio del buen gusto. (Nota 92)

[Se dice mal: --- / Debe decirse: bañero] El dueño de los baños, es como decimos jeneralmente; empleando cinco palabras por una, y empobreciendo el idioma. (Nota 31)

[Se dice mal: --- / Debe decirse: pañero] Vendedor de paños, es de lo que nos valemos para significar al traficante en este jénero; verbosidad inútil que tiende a empobrecer el idioma. (Nota 99)

El factor estético no deja de estar presente en las actitudes de Gormaz, aunque con menor frecuencia:

[Se dice mal: --- / Debe decirse: alcoba] En Chile, es casi desconocida esta palabra. Siempre nos valemos de cuarto de dormir; que a la par de larga y de mal gusto, puede reemplazarse tan castiza y económicamente. (Nota 11)

[Se dice mal: --- / Debe decirse: niñera]. Es casi totalmente desconocida entre nosotros esta voz. La sustituimos por ama seca, con mengua del idioma y sacrificio del buen gusto. (Nota 92)

En numerosas oportunidades usa argumentos de autoridad, aludiendo principalmente a Vicente Salvá y, en menor proporción, a la RAE. Sin embargo, para Gormaz la RAE tiene preeminencia por sobre Salvá, como puede verse en los siguientes ejemplos, en que lo que dice Salvá no obsta para censurar un uso, y sí en cambio importa mucho lo que dice la Academia: 
[Se dice mal: amolar, no existe / Debe decirse: molestar]. Tambien admite el señor Salvá, el verbo amolar, en sentido de molestar; que la Academia rejistra solo, en la significacion de afilar o sacar el corte o punta a una arma o instrumento cualquiera, en la muela o piedra de amolar. (Nota 19)

[Se dice mal: apeñuscar, no existe / Debe decirse: apañuscar]. Tambien trae este verbo [apeñuscar] el señor Salvá. (Nota 24)

[Se dice mal: calabazo, no existe / Debe decirse: calabacino]. Esta palabra [calabazo] la agrega el señor Salvá, contra la Academia que no la admite. (Nota 39)

Hay otros vocablos valorativos que Gormaz emplea con menor profusión. Por ejemplo, califica de "palabrerías" ciertas conductas lingüísticas del uso chileno:

[Se dice mal: --- / Debe decirse: nogueral]. Esta palabra se desconoce casi tambien entre nosotros. Muchos nogales; sitio de nogales; y otras palabrerias, empleamos en vez de un simple sustantivo. (Nota 94)

Por último, en cuanto al locus social y geográfico del "mal hablar", en varias ocasiones restringe la responsabilidad de los usos censurados al "vulgo":

[Se dice mal: cabalgar, en sentido de / Debe decirse: caballar]. Animal caballar, es como debe decirse; en lugar de animal cabalgar, que se emplea vulgarmente. Cabalgar, es subir o montar a caballo. (Nota 38)

[Se dice mal: vaguear, en sentido de / Debe decirse: vahear]. Vaguear, es lo mismo que vagar; y no el acto de echar vaho o vapor, con que se confunde vulgarmente. (Nota 146)

Sin embargo, en una cantidad mayor de ocasiones Gormaz usa un nosotros inclusivo, con lo cual (quizá como recurso retórico) se declara participante del sujeto del mal hablar chileno:

[Se dice mal: aquilón, en sentido de / Debe decirse: diaquilón]. Aquilon es un viento; y como entre nosotros se toma por el emplasto disecativo denominado diaquilon, es clara la impropiedad que apuntamos. (Nota 26)

[Se dice mal: carneraje, en sentido de / Debe decirse: carnerada]. Carneraje, es el derecho que se paga por los carneros; pero entre nosotros se emplea para demostrar un rebaño de carneros, lo cual es carnerada. (Nota 44)

[Se dice mal: --- / Debe decirse: pinole]. Esto es lo que se llama hulpo o chercan, entre nosotros. (Nota 110)

No puede dejar de llamar la atención, en cualquier caso, que, al hacer uso de nosotros, Gormaz diga específicamente entre nosotros: dentro del grupo en que él se incluye solo algunos, y no todos, practican los hábitos idiomáticos censurados. Además, siempre en estos casos el verbo aparece con un se impersonal, con lo cual contribuye a oscurecer la agentividad del verbo. El sujeto social 
del mal hablar, de esta manera, queda indefinido, pero, ya que antes Gormaz explícitamente había mencionado al vulgo, podría entenderse que esos "algunos" de "entre nosotros" son precisamente los sujetos de condición social baja.

\section{Conclusión}

Gormaz concebía claramente su obra como una "ayuda" para la educación idiomática de los chilenos en particular, en congruencia con lo que anticipa su título respecto de que sus "correcciones lexigráficas" tratan específicamente sobre "la lengua castellana en Chile". Esta finalidad, a su vez, se justifica en el contexto más amplio de formación de una nueva nación y de un pueblo civilizado funcional al nuevo Estado y al progreso de este. Es decir, en este autor puede apreciarse el vínculo estrecho que, para la mayoría de los estudiosos chilenos del lenguaje de la época, había entre lengua, política y educación. Cosa que no puede ser extraña si se tiene en cuenta la "impronta política" de la lexicografía y otros géneros metalingüísticos de la época de las independencias hispanoamericanas (Huisa, 2013), y la centralidad de la educación en la política de esta época.

El que la obra de Gormaz sea planteada por su propio autor como una "ayuda" implica que hay algo que remediar: los defectos en la forma de hablar español propia de los chilenos, que justificarían el carácter decididamente didáctico que adopta su discurso normativo-lingüístico. Por la misma razón, hay una modalidad deóntica que cruza transversalmente las diversas secciones del texto y que pretende asegurar la efectividad del proceso formativo asociado al texto. A partir de lo anterior, Gormaz despliega una serie de conceptualizaciones y valoraciones idiomáticas que muestran una actitud claramente negativa del español usado en Chile, en contraposición con el estándar culto codificado en obras normativas españolas (gramáticas y diccionarios de la RAE, o de Vicente Salvá) o de americanos partidarios de la unidad idiomática (Andrés Bello) y basado en la norma castellana. Es este modelo de lengua el que debe ser enseñado a los educandos chilenos, según nuestro autor.

Varios son los juicios en que se basa Gormaz para justificar su censura del uso chileno de la lengua española. El primero y más recurrente es el de la «inexistencia» de las variantes chilenas, afirmación que debe entenderse en el sentido de que exceden los límites impuestos por el estándar. Claramente, no se trata de variantes que puedan haberse considerado usos ocasionales (como destaca Sadowsky, 2011), debidos a meros errores, lo cual podría hacer más razonable la afirmación de Gormaz. Nuestro autor califica de "inexistentes" variantes que deben haber sido usadas profusamente en el español de Chile del XIX, y no solo en el habla popular, tales como las debidas al debilitamiento de /s/implosiva (arriejar < arriesgar). Se trata, simplemente, de que todo lo que se aparta del estándar es deslegitimado. 
La imagen de la lengua española que aparece en el discurso de Gormaz, entonces, es congruente con la ideología de la lengua estándar, principalmente por su inclinación monoglósica, es decir, propiciadora de la supresión de la variación lingüística en favor de una homogeneidad (funcional, por supuesto, para los afanes centralizadores de un Estado nacional). Los otros argumentos con que Gormaz justifica sus actitudes: efectividad comunicativa, apreciaciones estéticas, etc., constituyen más bien proyecciones o derivaciones secundarias del afán principal por asegurar una homogeneidad en el modelo de lengua que se habría de enseñar a los chilenos en la segunda mitad del siglo XIX. 


\section{Bibliografía}

Arnoux, Elvira Narvaja de (2008), Los discursos sobre la nación y el lenguaje en la formación del Estado (Chile, 1842-1862). Estudio glotopolítico, Buenos Aires, Santiago Arcos.

Azorín Fernández, Dolores (2003), "Un proyecto original en la lexicografía española: el Nuevo diccionario de la lengua castellana (1846) de Vicente Salvá”, en María Teresa Echenique y Juan Sánchez (eds.), Lexicografía y lexicología en Europa y América. Homenaje a Günther Haensch, Madrid, Gredos, p. 115-131.

Bartsch, Renate (1982), “The concepts 'rule' and 'norm' in linguistics”, Lingua, vol. 58, p. 51-81.

Bello, Andrés (1847), Gramática de la lengua castellana destinada al uso de los americanos, Santiago (Chile), Imprenta del Progreso.

Blommaert, Jan, (ed.) (1999), Language Ideological Debates, Berlin/New York, Mouton de Gruyter.

Camacho, Aurora (2003-2004), "Huellas ideológicas en la lexicografía cubana”, Revista de Lexicografía, vol. 10, p. 21-38.

Cameron, Deborah (1995), Verbal Hygiene, London/New York, Routledge.

Chuchuy, Claudio (1994), "Rasgos contrastivos y diferenciales en los diccionarios nacionales del español de América del siglo XIX”, en Gerd Wotjak y Klaus Zimmermann (eds.), Unidady variación léxicas del español de América, Frankfurt/Madrid, Vervuert/Iberoamericana, p. 83-103.

Coseriu, Eugenio (1990), “El español de América y la unidad del idioma”, en Actas del I Simposio de Filología Iberoamericana, Zaragoza, Pórtico, p. 43-75.

Del Valle, José y Luis Gabriel-Stheeman, (eds.) (2004), La batalla del idioma. La intelectualidad hispánica ante la lengua, Madrid/Frankfurt, Iberoamericana/Vervuert.

DUECh = Academia Chilena de la Lengua (2010), Diccionario de uso del español de Chile (DUECh), Santiago (Chile), MN Editorial.

Ferreccio, Mario (1979), "Las fuentes de la filología chilena. I. El catálogo anónimo de 1843”, Atenea, n 440, p. 39-59.

Girón Alconchel, José Luis (2007), "Corrientes y períodos en la gramática española”, en Josefa Dorta, Cristóbal Corrales y Dolores Corbella (eds.), Historiografía de la lingüística en el ámbito hispánico. Fundamentos epistemológicos y metodológicos, Madrid, Arco/Libros, p. 59-88.

Gormaz, Valentín (1860), Correcciones lexigráficas sobre la lengua castellana en Chile, Valparaíso, Imprenta del Comercio.

Haensch, Günther (2000), "Introducción”, en Textos clásicos para la historia de la lexicografía del español en América [CD-ROM, Colección Clásicos Tavera], Madrid, Fundación Histórica Tavera/ Fundación MAPFRE. 
Huisa, José Carlos (2013), "La impronta política en la primera lexicografía hispanoamericana: republicanismo y antirrepublicanismo”, Lexis, vol. 37, n² 2, p. 269-303.

Matus, Alfredo (1994), "Períodos de la lexicografía diferencial del español de Chile", en Actas del X Congreso de la Asociación de Academias de la Lengua Española, Madrid, RAE-Espasa Calpe, p. 189-199.

Milroy, James y Leslie Milroy (1999), Authority in Language: Investigating Standard English, London, Routledge.

Milroy, James (2001), "Language ideologies and the consequences of standardization", Journal of Sociolinguistics, vol. 5, n 4, p. 530-555.

Morales Pettorino, Félix, Óscar Quiroz y Dora Mayorga (1969), Los verbos en -ear en el español de Chile, Santiago (Chile), Editorial del Pacífico.

Moreno Fernández, Francisco (2009), La lengua española en su geografía, Madrid, Arco/Libros.

NGLE-Manual = Real Academia Española y Asale (2010), Nueva gramática de la lengua española. Manual, Madrid, Espasa.

Niedzielski, Nancy y Dennis R. Preston (2003), Folk Linguistics, Berlin/New York, Mouton de Gruyter.

Roca Franquesa, José María (1953), "Las corrientes gramaticales en la primera mitad del siglo XIX: Vicente Salvá y su influencia en Andrés Bello", Archivum, 3, p. 181-213.

Rodríguez, Zorobabel (1875), Diccionario de chilenismos, Santiago, Imprenta de "El Independiente".

Rojas Carrasco, Guillermo (1940), Filología chilena. Guía bibliográfica y crítica, Santiago (Chile), Imprenta y Literatura Universo.

Rojas, Darío (2010), "Estandarización lingüística y pragmática del diccionario: forma y función de los 'diccionarios de provincialismos' chilenos", Boletín de Filología, vol. XLV, nº 1, p. 209-233.

Rojas, Darío (2015), "Ideologías y actitudes lingüísticas en el Chile del siglo xix: los reparos de Andrés Bello a las Correcciones lexigráficas de Valentín Gormaz", Lexis, vol. 39, nº 1, p. 163-181.

Sadowsky, Scott (2011), "El cofre de tesoro de Valentín Gormaz", Tercera Cultura [en línea], 12 de junio de 2011, disponible en http://terceracultura.cl/2011/06/el-cofre-de-tesoro-de-valentingormaz/ [página consultada el 22 de noviembre de 2014].

Serrano, Sol (2010), "Educar al nuevo soberano. Chile entre 1810 y 1814", Bordón, vol. 62, n², p. 29 38.

Torrejón, Alfredo (1989), "Andrés Bello, Domingo Faustino Sarmiento y el castellano culto de Chile", Thesaurus, vol. 44, n³, p. 534-558.

Trudgill, Peter (1998), "The Meaning of Words Should Not be Allowed to Vary or Change", en Laurie Bauer y Peter Trudgill (eds.), Language Myths, London, Penguin, p. 1-8. 
Trujillo-González, Verónica (2013): "Los libreros franceses y el desarrollo de la lexicografía española e hispanoamericana del siglo XIX: difusión e influencia", Études Romanes de Brno, vol. 34, n², p. 9-22. 